\title{
How Do National Cultures Affect Quality of Life in Europe During the COVID-19 Pandemic?
}

\author{
Somjintana Koompai ${ }^{{ }^{*} \oplus \text {, }}$ Joël Royer ${ }^{2}$

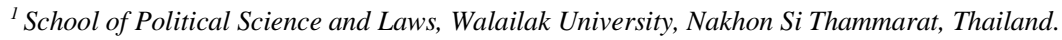 \\ ${ }^{2}$ Service Management Department, La Poste, Paris, France.
}

\section{Abstract}

Objectives: This study aimed to explore the six cultural dimensions of Geert Hofstede that affect perceptions of quality of life in 26 European countries during the COVID-19 pandemic (April 2020-March 2021): (1) Quality of life, (2) Democracy and trust, (3) Working during COVID-19, (4) Financial situation, (5) Support during COVID-19, and (6) Health care during COVID-19. Many studies are not conclusive on which dimensions of national culture affect the spread and death rate of COVID-19. The researchers, therefore, consider that studying the pandemic from the perception of quality can prevent its spread and contribute to the care and security of people affected by COVID-19. This study may be another way of providing information to those stakeholders. Method: To determine which aspects of culture affect the quality of life of Europeans during the COVID-19 pandemic, the researchers analyzed data through stepwise multiple regression analysis to predict the relationship between independent variables (cultural dimensions) and dependent variables (perceptions of the quality of life). Findings: It was found that during the COVID-19 pandemic, countries with higher power distance and higher uncertainty avoidance had a lower quality of life in several dimensions, mainly in Eastern European countries and Latin European countries (France, Italy, Portugal, and Spain). In the Nordic or Scandinavian countries with higher levels of indulgence, people were more satisfied with their quality of life in spite of the COVID-19 epidemic. Novelty/Improvement: The results may inform policy-makers and stakeholders on how national cultures have both positive (i.e., indulgent and long-term) and negative (high power distance and high uncertainty avoidance) effects on the quality of life of Europeans during the COVID-19 pandemic. There should be (1) short-term measures to provide equal economic measures and public health assistance to reduce anxiety (reduce high power distance and high uncertainty avoidance), (2) medium-term measures to promote education and training to prepare people for new modes of working in the future (decrease high uncertainty avoidance), and (3) long-term measures to cultivate cultures to save for the future and to be optimistic and happy, both mentally and physically (increase long term orientation and indulgence).

\section{Keywords:}

National Cultures;

Quality of life;

Europe;

During the COVID-19 Pandemic.

\section{Article History:}

$\begin{array}{llll}\text { Received: } & 28 & \text { September } & 2021 \\ \text { Revised: } & 20 & \text { November } & 2021 \\ \text { Accepted: } & 18 & \text { December } & 2021 \\ \text { Published: } & 07 & \text { February } & 2022\end{array}$

\section{1- Introduction}

Coronavirus or COVID-19, emerged at the end of 2019 and quickly spread to all continents of the world. As of August 31, 2021, there were approximately 216 million cases of COVID-19 and 4.5 million deaths [1]. It is not just causing a global public health crisis; it is also leading to severe economic and social crises. Therefore, governments of all countries are looking for ways to prevent the pandemic and treat people infected with the virus, such as lockdowns, curfews, prohibiting foreigners from entering their countries, a 14-day quarantine for travelers from abroad, the mandatory use of masks when going outside, and social distance. The implementation of government policies in all countries inevitably affects people's lives, although lockdown and working from home during the epidemic have had a

\footnotetext{
*CONTACT: ksomjint@wu.ac.th
}

DOI: http://dx.doi.org/10.28991/esj-2022-SPER-02

(C) 2022 by the authors. Licensee ESJ, Italy. This is an open access article under the terms and conditions of the Creative Commons Attribution (CC-BY) license (https://creativecommons.org/licenses/by/4.0/). 
positive impact on family support and mental health awareness. However, the government needs to continually increase people's access to mental health care. Mental health problems are due to the effects of the COVID-19 pandemic, such as lower income, layoffs, unemployment, and inequality in access to health care among low-income and ethnic minority groups [2]. Self-employment and small- and medium-sized enterprises (SMEs) are at risk in marketing, finance, and personnel [3].

Grané et al. [4] found that the COVID-19 pandemic has resulted in lower levels of economic and health (mental and physical health) vulnerability among Europeans. Levels of vulnerability vary across regions of Europe, the most vulnerable being Eastern European countries. Eurofound [5] surveyed the quality of life, work, government support, and public health systems during the COVID-19 outbreak from June 2020 to April 2021 and found that Europeans of all ages, especially young people and unemployed individuals have reduced happiness and that existing inequality has widened, and disadvantaged and marginalized individuals are the largest at risk group. Citizens greatly decreased satisfaction with crisis policies and rules and requested assistance from the government. Some Europeans lack trust in their government, and more than a quarter of them are hesitant about the COVID-19 vaccine [6]. However, each country in Europe has different cultures or ways of life, even though they are on the same continent. France and Germany, for example, share borders, but the French have higher levels of power distance and uncertainty avoidance than Germans [7-9]. They are very afraid of uncertainty and give importance to high positions. Meanwhile, Germans have higher masculinity and long-term orientation than do the French [7-9], and they are more assertive toward institutions than groups, work for their future, focus on job success, and dare to take risks.

This research aimed to study the effect of national culture on the quality of life of Europeans during the COVID-19 outbreak. However, European countries have different cultures, so they may have different quality of life perceptions during the COVID-19 crisis. Culture is a people's way of life and affects the quality of life in their societies [10, 11]. Culture makes people have different beliefs, values, and attitudes depending on their ways of life. The same experience may be interpreted differently by people because of the influence of their cultures. During the COVID-19 crisis, national cultures also affected each country's response to the epidemic. Some researchers encountered high power distance [12], and countries with high uncertainty avoidance could control the spread of COVID-19 better than countries with high individualism [13, 14] and indulgence [15, 16]. However, in some cases, the effects are the opposite: high power distance countries further contribute to the expansion of the virus [17], and high individualism affects the success of a nation in controlling the COVID-19 pandemic [12].

This study examines how national cultures affect the quality of life of Europeans during the COVID-19 pandemic. The quality of life has significant implications for social and public policy in every country [10, 11]. However, defining quality of life policies requires taking into account the values, beliefs, lifestyles, and cultures of the people of the country. Studying cultures and the quality of life during the COVID pandemic requires data to prevent the spread of the virus and to care for and heal people affected by COVID-19. It may be empirical information for those stakeholders. In this article, the researchers present the study process and research results as follows.

- Summary of a review of literature on European national cultures and a study of the quality of life of Europeans during the COVID-19 outbreak (April 2020-March 2021).

- The research methodology to identify the relationship between national cultures and quality of life during COVID-19.

- The detailed results of the study on how national culture affects Europeans' recognition of the quality of life in times of crisis are presented in charts.

- The results are discussed in detail and compared with other similar studies.

- The results are summarized and suggestions are provided to stakeholders.

\section{2- Literature Review and Conceptual Framework}

\section{2-1-Cultural Dimensions}

Power Distance (PDI): is the level to which people value social status and equality. In some societies, citizens are different because they are divided between classes, positions, privileges, and social status, such as boss and subordinate, rich and poor, and high-ranking people with power have more privileges than those of lower ranks. Lowranking individuals have difficulty obtaining higher social status because they are controlled or excluded from the high classes; therefore, they accept unequal decentralization and believe that social inequality is normal. Societies with high inequality are called "high power distance" cultures. However, in societies with low power distances, people have equal rights, and most of them are middle class. High-rankers use their powers and privileges when necessary. According to research by Hofstede [8, 9], developing countries tend to have a high power distance; in contrast, a low power distance societies show democratic behaviors [18]. However, during the COVID-19 pandemic, countries with high power distance levels have been able to prevent the spread of COVID-19 very well. This is because the country's leaders have rules for people to follow strictly, while in low power distance countries, governments enacted policies by asking people to make decisions in their interest, relying on voluntary measures rather than coercion [18]. 
A second dimension is individualism versus collectivism (IDV): Individualism refers to people only being interested in themselves or their families and people close to them, who want to focus on their interests, such as making decisions by themselves, or who value respect for privacy and individual abilities and achievements [8,9]. In contrast, collectivism places importance on the relationship between members within their groups, such as family, relatives, educational institutions and organizations. Collectivist societies are loyal to their groups, they focus on the benefits of groups before personal interests, and make decisions by groups. Although collectivists focus on relationships, they always focus on relationships only within their groups; they distrust or do not want to build new relationships with those who are outside their groups [19].

Masculinity or Tough versus Femininity or Tender (MAS): Masculinity prioritizes success, courage, assertiveness, the need for money or objective rewards as success. People like competition, want to be the winners, and live to work. Masculine countries prioritize economic growth and give more importance to men than women, so men have more opportunities than women. In contrast, feminine countries emphasize cooperation, compromise, modesty, caring for the disadvantaged, and quality of life. People work for their living or work to live, men and women are equal, and they prioritize environmental protection rather than financial growth.

Uncertainty Avoidance Index (UAI): expresses the attitude of members of societies toward uncertainty and ambiguity. If they do not like uncertainty or often worry about ambiguity and try to control it by issuing regulations clearly to follow consistently, these are considered high uncertainty avoidance or conservative societies. However, some societies see change as natural and, thus, do not worry about what will happen in the future. They have flexible rules that can be adjusted accordingly. In politics, citizens in high uncertainty avoidance countries have little interest in politics, and governments do not like public protests because they cause chaos. In contrast, in countries with low uncertainty avoidance, people are very interested in politics and go to protests because they are tools of change. However, it was found that countries with high uncertainty avoidance had lower rates of COVID-19 than those with low uncertainty avoidance [20].

Long-Term Orientation versus Short-Term Orientation (LTO): Long-term orientation societies tend to uphold traditions and social norms, are tolerant, frugal, and save for the future. Short-term orientation societies have the opposite characteristics; they aim at short-term results, spend for life today rather than save for the future and maintain face.

Indulgence versus Restraint (IVR): refers to the degree of control over individual desires or needs. A high level of indulgence level means a person seeks happiness or to satisfy their needs openly. If the indulgence level is low, in other words, restraint, individuals control their needs by creating strict social rules of expression. Countries with high levels of indulgence are also found to have high rates of mortality from COVID-19 [15, 17].

\section{2-2-European Cultures}

Europe has many countries and cultures. Calori and de Woot [21] and Schwartz [22] classified European countries according to their cultural dimensions, which is similar to the research of House et al. [7] and Trompenaars and Hampden-Turner [23]. Group I Scandinavian Group or Nordic Group [7]: Denmark, Finland, Sweden, and The Netherlands [21]. The Nordic Group has high individualism (The Netherlands, Denmark, Sweden, Norway, and Finland), but House et al. [7] found that the Nordic Group has high collectivism values. It also has low masculinity or high femininity (Sweden, Norway, and Denmark), low power distance (Sweden), and focuses on long-term orientation or the future [7]. Group II Anglo-Saxon Group is the English-speaking group. Ireland and England have high individualism and masculinity, but House et al. [7] found that they have high collectivism and high femininity, including high indulgence. Trompenaars and Hampden-Turner [23] found that British people do not like to express their emotions openly (restraint), have high power distance, and have low uncertainty avoidance. Group III Germanic Group: Austria, The Netherlands [7], Switzerland (German speaking), and Germany have high individualism values (the Netherlands, Switzerland, and Germany), but Trompenaars and Hampden-Turner [23] and House et al. [7] argued that Germany has high collectivism or less individualism. These countries also focus on being tough or highly performance-oriented (Austria and Switzerland) [7], long-term results (Germany and Switzerland), and low power distance (Austria). Group IV Latin European: Its component countries, Belgium, Italy, Switzerland (French speaking), Spain, Portugal, and France, are highly individualistic, such as Italy and Belgium. Their cultures are high uncertainty avoidance and high power distance (Belgium and France) [8, 9, 23]. However, House et al. [7] found that such countries have low power distance values. Group V Eastern Europe [7]: Greece, Hungary, Albania, Slovenia, Poland, Russia, Georgia, and Kazakhstan were the countries that separated from the Soviet Union after the end of the Cold War. Their cultures are high uncertainty avoidance (Greece and Slovakia) and high power distance (Russia and Ukraine) [23]. This contradicts House et al. [7], who found that the Eastern Europe group has low power distance and that the former communist countries (Czechoslovakia and the Soviet Union) are individualistic [23] and have low indulgence (Bulgaria, Lithuania, and Ukraine). 


\section{2-3-Quality of Life (QOL)}

Quality of life (QOL) is the individuals' perception of their lives in the environment and the societies they live in or interact with [24]. Scholars want to assess what they perceive as satisfaction or dissatisfaction, such as marriage, interpersonal relationships, work, leisure activities, and health, including well-being and/or welfare, and what they like or dislike about their living environments [25-27]. To measure quality of life, empirical data called the Perceived Quality of Life Scale (PQoL), developed from a variety of theories, such as human needs theory from psychology and sociology, must be available. [28, 29]. In addition, interviews about the level of satisfaction with life and society are also used to obtain accurate quality indicators [30].

During the COVID-19 pandemic, the EU Agency for the improvement of living and working conditions, or Eurofound [31] (2021), (measured the quality of life of Europeans from April 2020 to March 2021 to know how they feel about (1) quality of life during COVID-19, (2) democracy and trust, (3) working during COVID-19, (4) financial situation and security, (5) quality of public services during COVID-19, (6) support measures and (7) vaccination. [31]. the survey found that countries perceive their quality of life to have declined during the COVID-19 pandemic, but this decline in quality of life varies in each country. The quality of life in some countries has fallen considerably, but in other countries it has dropped less.

\section{3- Research Methodology}

The relationship between national cultures (independent variables) and quality of life during COVID-19 (dependent variables) was determined according to Figure 1.

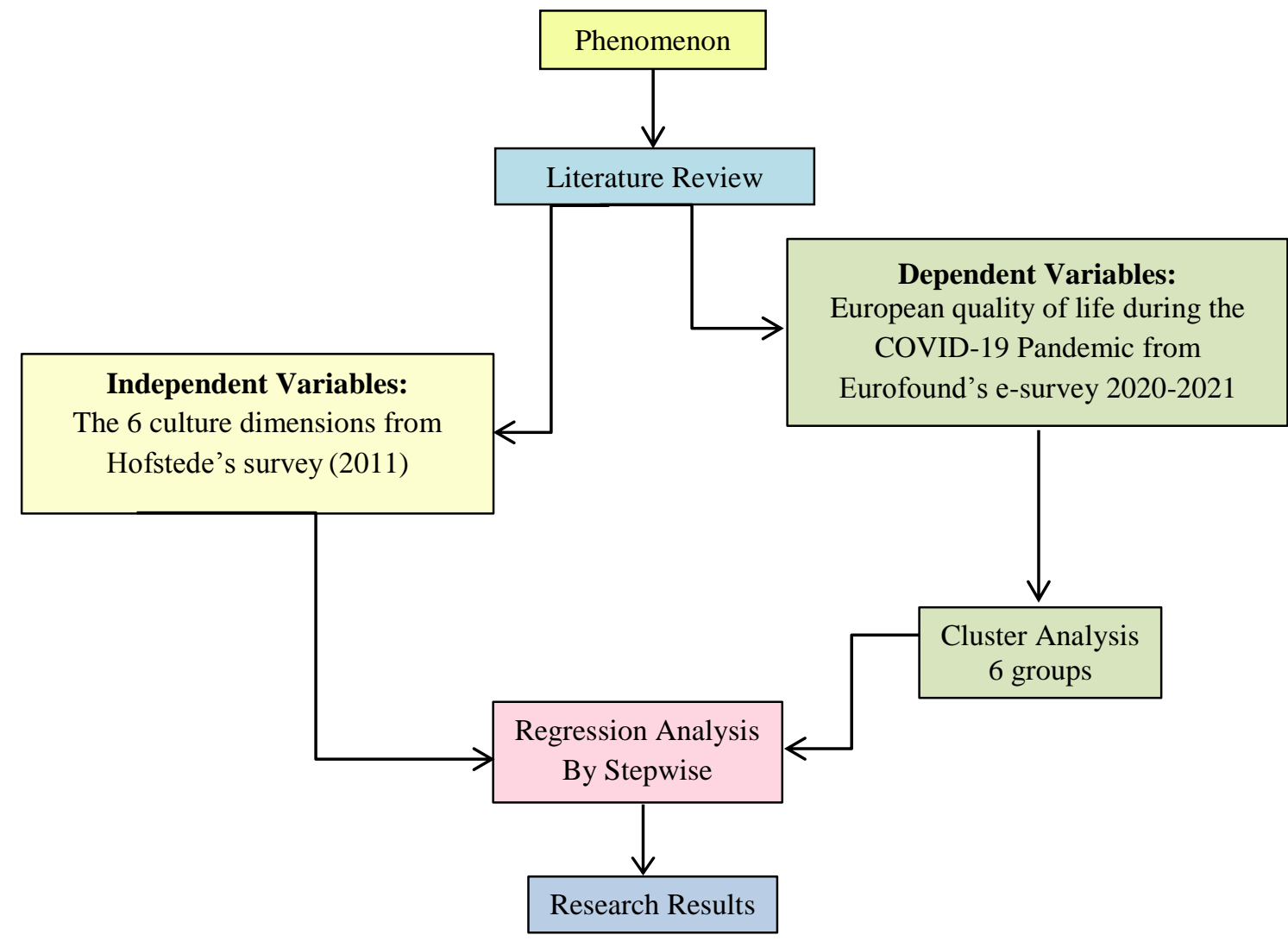

Figure 1. Flowchart of finding the relationship between independent variables and dependent variables

The researchers performed the research methodology as follows:

1) The independent variables selected were the six cultural dimensions of Hofstede [8, 9], as discussed in the literature review, and the dependent variables were secondary data of the quality of life of 26 European countries: (1) Austria, (2) Belgium, (3) Bulgaria, (4) Czechia, (5) Germany, (6) Denmark, (7) Estonia, (8) Greece, (9) Spain, (10) Finland, (11) France, (12) Croatia, (13) Hungary, (14) Ireland, (15) Italy, (16) Lithuania, (17) Luxembourg, (18) Latvia, (19) Malta, (20) Netherland, (21) Poland, (22) Portugal, (23) Romania, (24) Sweden, (25) Slovenia, and (26) Slovakia.

2) The data from the Eurofound survey was used to categorize the quality of life by cluster analysis into six large groups because the researchers wanted to combine the quality of public services during COVID-19 with vaccinations. European quality of life information was based on Eurofound's 2020-2021 e-survey on (1) Quality 
of life during COVID-19, (2) Democracy and trust (3) Working during COVID-19 (4) Financial situation and security (5) Quality of public services during COVID-19 (6) Support measures, and (7) Vaccinations, which took place in 3 phases:

- Phase 1: April 2020, when European countries announced the lockdown for the first time.

- Phase 2: July 2020, when Europe's economy and society eased the lockdown.

- Phase 3: March 2021, during which many European countries closed their countries again.

The researchers analyzed the data with cluster analysis to identify cases that were identical or similar to the same group. The data are different from the other data, and they are in other groups. The cluster analysis was able to classify 6 variables, which are similar to the grouping of Eurofound: (1) Quality of life, (2) Democracy and trust, (3) Working during COVID-19, (4) Financial situation, (5) Support services during COVID-19 and (6) Health care during COVID-19, as shown in Figure 2.

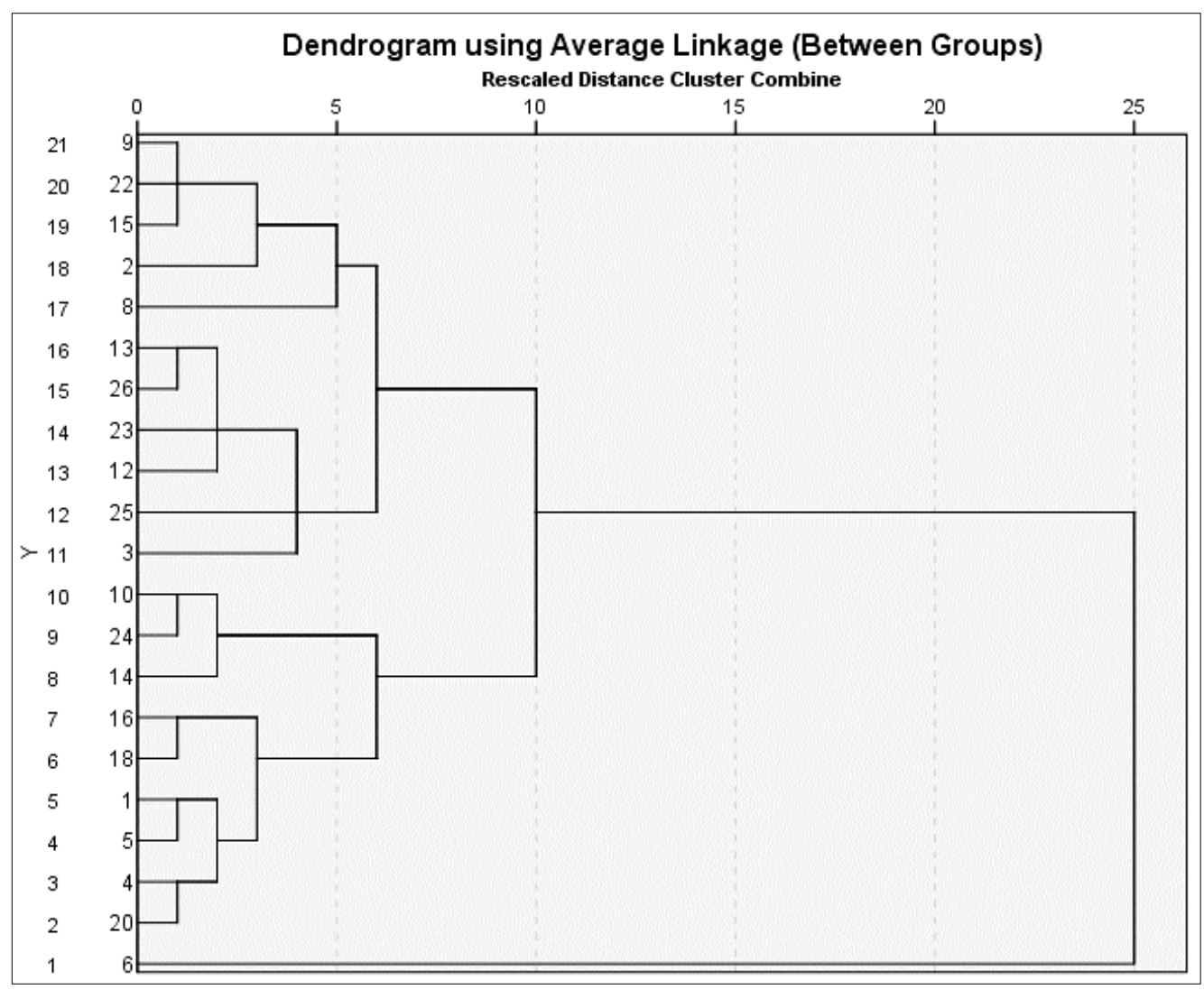

Figure 2. Cluster Analysis result

3) Applied the six dimensions of Hofstede's national culture from the 2011 survey to predict European perceptions of quality of life by multiple regression analysis.

- The 6 variables of national culture were analyzed for their relationships to protect the multicollinearity problem.

- We analyzed how each culture dimension affects the perception of quality of life with stepwise regression analysis. We analyzed the relationship between several independent variables and one dependent variable to study whether any independent variables could predict or explain the variation in the dependent variables. In such statistical analysis, if the statistical significance is less than 0.05 , it means that the independent variables (cultural dimensions) affect the dependent variables (quality of life).

\section{4- Results}

Before analyzing the cultural dimensions that affect the quality of life of Europeans during the COVID-19 pandemic by multiple regression analysis, the researchers analyzed the correlation between the six independent variables. This is because many independent variables may be related and thus lead to a violation of the main assumption of multiple regression analysis. The independent variables should not be highly correlated with values close to 1 . The relationship between the independent variables of this research is shown in Table 1. 
Table 1. Relationship between independent variables (six cultural dimensions)

\begin{tabular}{|c|c|c|c|c|c|}
\hline Culture Dimension & Power Distance & Individual & Masculinity & Uncertainty & Long term \\
\hline Individual & $-0.409^{* *}$ & & & & \\
\hline Masculinity & 0.047 & 0.073 & & & \\
\hline Uncertainty & $0.489^{* *}$ & $-0.314^{*}$ & 0.227 & & \\
\hline Long term & -0.044 & 0.155 & -0.031 & -0.088 & \\
\hline Indulgence & -0.241 & 0.177 & 0.041 & -0.190 & $-0.286^{*}$ \\
\hline
\end{tabular}

** Correlation is significant at the 0.01 level (2-tailed).

* Correlation is significant at the 0.05 level (2-tailed).

Table 1 presents the correlation between the independent variables and the six Hofstede cultural dimensions for analyzing the effect on the quality of life of Europeans during the COVID-19 outbreak as dependent variables. No pair of independent variables was found to be highly correlated, and thus did not cause assumption violations for multiple regression analysis. This makes it possible to present the results of the stepwise analysis in Table 2.

Table 2. Culture dimensions that affect the quality of life of Europeans during the COVID-19 pandemic

\begin{tabular}{|c|c|c|c|c|c|c|c|c|}
\hline Quality of life during COVID-19 & (Constant) & PDI & IDV & MAS & UAI & LTO & IVR & $\mathbf{R 2}$ \\
\hline 1.1 Mental well-being & 56.102 & -0.332 & -0.063 & -0.358 & $-0.523 *$ & 0.019 & 0.091 & 0.274 \\
\hline 1.2 Life satisfaction & 7.112 & $-0.664 *$ & 0.141 & -0.202 & -0.153 & -0.099 & 0.219 & 0.440 \\
\hline 1.3 Happiness & 7.184 & $-0.593 *$ & 0.134 & -0.264 & -0.243 & -0.086 & 0.286 & 0.351 \\
\hline 2.1 Democracy & 5.774 & $-0.655^{*}$ & 0.055 & -0.208 & -0.245 & 0.005 & $0.353^{*}$ & 0.684 \\
\hline 2.2 Government & 5.245 & $-0.600 *$ & -0.029 & -0.182 & -0.234 & 0.024 & $0.386^{*}$ & 0.640 \\
\hline 2.3 Optimism about future & 73.663 & $-0.417 *$ & -0.270 & -0.244 & $-0.477^{*}$ & -0.070 & -0.061 & 0.590 \\
\hline 2.4 Country’s future & 67.509 & $-0.553 *$ & -0.269 & -0.123 & $-0.399 *$ & -0.129 & 0.135 & 0.674 \\
\hline 3.2 Job worry & 7.542 & 0.277 & 0.091 & -0.010 & $0.673^{*}$ & -0.070 & 0.078 & 0.452 \\
\hline 3.3 WHF satisfaction & 59.399 & -0.225 & 0.036 & 0.285 & -0.032 & 0.055 & $0.463^{*}$ & .0 .214 \\
\hline \multicolumn{9}{|l|}{ 4. Financial situation } \\
\hline 4.1 Present finances & 43.496 & $-0.501 *$ & 0.122 & -0.236 & -0.221 & $0.305^{*}$ & $0.558^{*}$ & 0.650 \\
\hline 4.2 Future finances & 21.599 & $-0.578 *$ & 0.273 & -0.260 & -0.215 & 0.266 & $0.336^{*}$ & 0.550 \\
\hline \multicolumn{9}{|l|}{ 5. Supporting during COVID-19 } \\
\hline 5.1 Financial support & 12.244 & -0.004 & -0.004 & 0.020 & 0.016 & $-0.082 *$ & $-0.073 *$ & 0.362 \\
\hline 5.2 Other support & 3.290 & -0.021 & -0.004 & $-0.086^{*}$ & 0.126 & -0.063 & 0.530 & 0.402 \\
\hline
\end{tabular}

* Statistically significant $<0.05$ level

From Table 2, the relationship between national cultures and the quality of life of Europeans during the COVID-19 pandemic can be explained as contents and Figures 3 to 8. Each figure shows correlation trends between the cultural dimensions and the quality of life of Europeans during the COVID-19 pandemic. The researchers describe only the statistically significant (sig $<0.05$ level) relationship in each figure.

\section{4-1-Quality of life: Mental Well-Being, Life Satisfaction, and Happy}

Figure 3 shows that four cultural dimensions have either completely reduced perceptions of one's quality of life or were in the opposite direction during the COVID-19 pandemic. The analysis found that people in countries with higher uncertainty avoidance (UAI) had significantly lower levels of mental well-being (27\% prediction value), mainly Eastern Europe and Latin Europe countries, such as France (PDI = 68), Spain (PDI = 57), and Italy (PDI = 50), which were among the top rates of infection, illness and mortality from COVID-19 in the world [1]. These factors affect the minds of the people, causing fear, anxiety, loss of family members, difficulty in life and economic hardship, including other unpredictable phenomena due to COVID-19 [32]. In particular, vulnerable individuals, people with 
handicaps, underprivileged individuals, homeless individuals, and poor individuals suffered from greater health inequalities. The spread of COVID-19 resulted in a disproportionate increase in morbidity and mortality, affecting mental health, non-hygienic behavioral problems, and reduced quality of life [33]. For example, in the Seine-SaintDenis department of France, poor, multiethnic immigrants who live there are most at risk of being affected by COVID-19; it is a source of the spread of disease. Workers are affected more than managers; they must go to work almost every day, and their work is such that they cannot maintain social distance. Those most at risk are health professionals (nurses, care assistants, doctors, etc.) or people who constantly engage in certain activities (agricultural workers, non-skilled salespeople, self-service staff, police officers, etc.) [34].

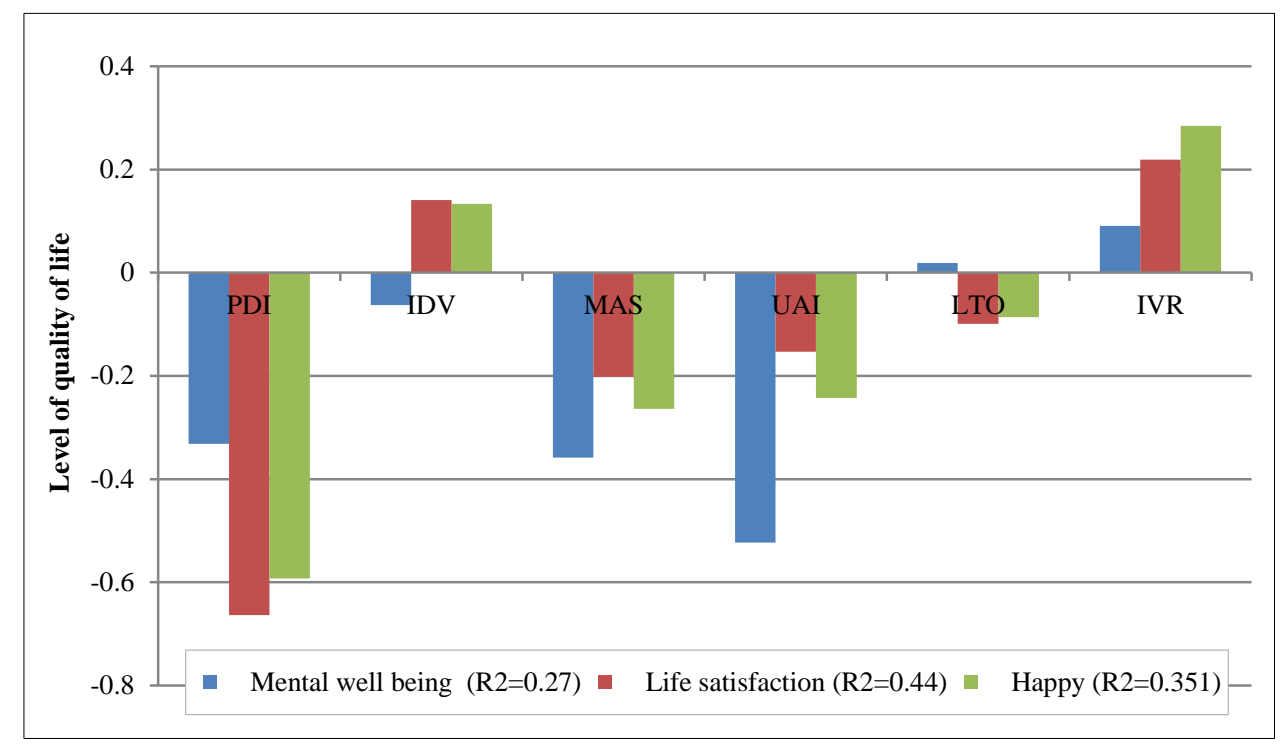

Figure 3. Quality of life

The life satisfaction and happiness of Europeans during the COVID-19 pandemic showed that countries with higher power distance (PDI) had significantly lower levels of life satisfaction and happiness (44\% and 35\% prediction values, respectively). This research found that, during the COVID-19 epidemic in mid-2020 to mid-2021, countries with high power distances, such as Bulgaria $(\mathrm{PDI}=70)$ and Greece $(\mathrm{PDI}=60)$, both of which have widespread inequalities among women, young people, and marginalized people, were affected by unemployment, a difficult work-life balance, and financial instability [31]. Bulgarians have income inequality despite expanding domestic markets, but income distribution and tax collection cannot be performed as expected, causing public spending to decrease. In addition, the COVID-19 crisis tends to increase income inequality, including gaps in economic policy implementation [35].

The first lockdown in Greece disrupted cities and everyday life and led to wider social inequalities. Work and lifestyle have changed dramatically, and many employees have to work from home. Women tend to work from home more than men, making them work more in terms of workload and duration, which seriously impacts working hours and productivity. Most students do not like online learning, especially students enrolled in higher education. The second wave outbreak created uncertainty at all levels of the economy and work life and slowed recovery. Wage inequality regulates employment conditions. Workers' salaries have been cut and they have lost income; the decline in earnings has led to pessimism about compensation, career development, work conditions, private lives, mental conditions. Overall, their life balance is unstable. There was growing concern among private-sector workers about changes in wages and labor conditions. In addition, the economic impact created inequality between households, especially middle-income households. On the other hand, the gap between the income of the poor and the wealthiest households has increased. Brain [36] has seen that even in professions such as professional workers, doctors, teachers, solicitors, and managers, considered high-status occupations, people feel that their career status has declined. This decreased feeling negatively affects their self-efficacy while increasing work-life conflicts [37].

In conclusion, during COVID-19, Europeans with high uncertainty avoidance (UAI) perceived their mental wellbeing to decline, and those with high power distance (PDI) were less satisfied in life and less happy.

\section{4-2-Democracy and Trust during COVID-19}

Researchers chose satisfaction with the country's democracy, trust in governments and optimism about their future, and opinions on the country's future. The National Educational Panel Study (NEPS) has shown a sharp decline in life satisfaction after the COVID-19 outbreak, and people had a lower level of trust in institutions or individuals such as governments, courts, or the media [38]. 
Figure 4 shows that countries with higher power distance (PDI) are significantly less satisfied with democracy (68\% prediction value). For example, Poland had high power distance (PDI $=68)$ and low satisfaction with democracy because Poland has been characterized as an illiberal democracy [39] since 2015. The Law and Justice Party (PIS), the conservative opposition party of Poland, has policies against the European Union (EU) and opposes the admission of EU immigrants. The PIS has a socially conservative policy and promotes more traditional values that do not support women's rights or LGBT rights. LGBTQ+ marriage and child custody are illegal; additionally the government has tried to control freedom of the press during the COVID-19 outbreak [40]. The Polish government took action on two issues: anti-crisis and financial protections. Despite the difficult and volatile situation caused by the pandemic, the state of emergency was never declared, which is now one of the key arguments used by the business community questioning the governmental restrictions curbing operations of numerous sectors of the economy [41].

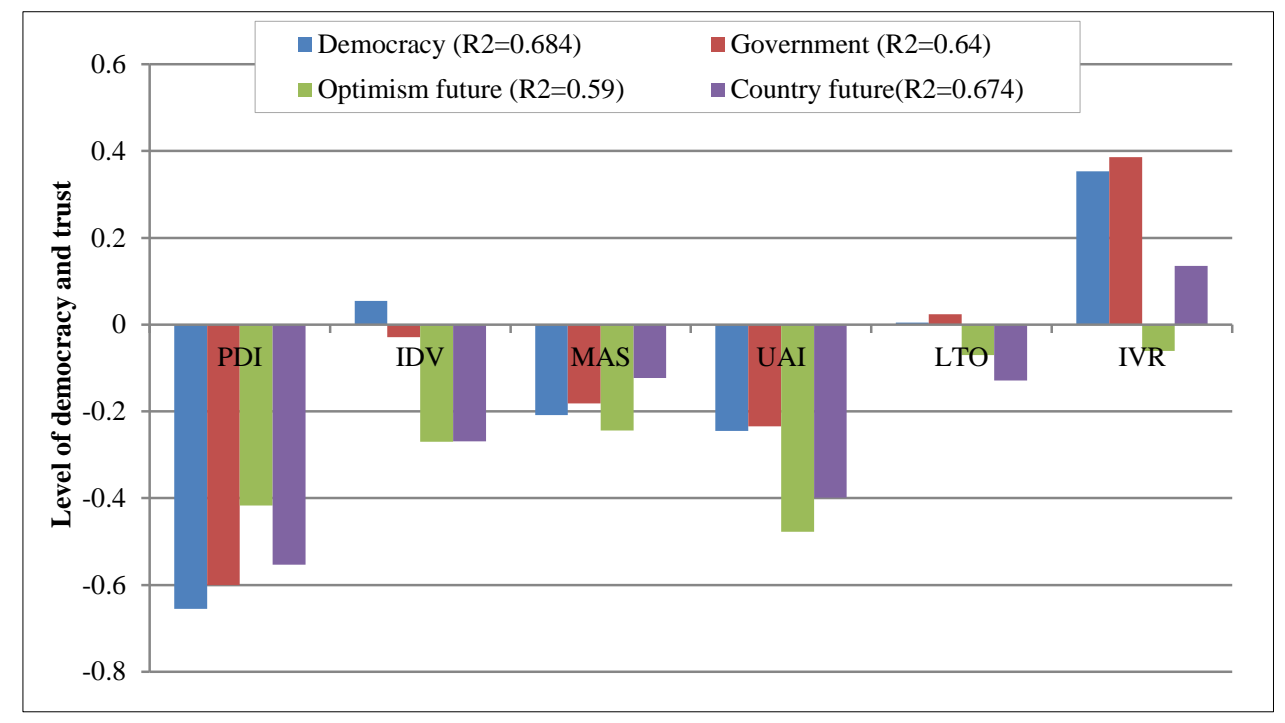

Figure 4. Democracy and trust during COVID-19

Trust in their governments: Respondents in countries with higher power distance (PDI) had significantly less trust in their government during the COVID-19 outbreak (64\% predicted value), such as Bulgaria (PDI = 70) and Poland (PDI = 68). In particular, Bulgarian young people were dissatisfied with the government administration and protested against the president, calling for him to resign. The protests were frequent due to their view that the government is corrupt, that it threatened the freedom of the media, which is contrary to the principles of democracy, and caused the compensation of some groups of the population to decrease [42]. In addition, the leaders of Poland and Bulgaria became infected with COVID-19 in October 2020 [43], causing greater distrust among the people in the government's handling of the COVID-19 outbreak. However, the respondents in countries with higher indulgence (IVR) also had significantly higher confidence in democracy and trust in their governments $(68 \%$ and $64 \%$ predictive values, respectively). For example, in Denmark (IVR =70), the Danish government responded to the COVID-19 epidemic quickly and realized that private businesses would have to shut down to contain the virus. The government regulated a number of important support measures to mitigate the impact of COVID-19 on working and living conditions through expeditious policy-making by parliament. It also allows social partners to participate in most of the new agreements, in particular, agreements aimed at preventing severe unemployment impacts [44]. Danish people are flexible, tolerant, aware of their impulses and desires, enjoy life, have a positive attitude, and have an optimistic view of the world. Danes know how to deal with COVID-19 without panicking because the government provides knowledge about COVID simply, clearly communicates only useful information to the public to understand quickly and put into practice the correct measures. People willingly cooperate with the government because the government announced, "The government will do everything possible to protect the people of Denmark" [45]. Access to epidemic information was strongly correlated with life satisfaction [46], so the Danish have a good attitude and are optimistic that what the government does is truly for them. There are no hidden agenda benefits; therefore, they comply with the government unconditionally.

Regarding optimism about their future and the future of 26 European countries, higher power distance (PDI) and higher uncertainty avoidance (UAI) countries were more likely to look at their own future, and the future of their countries was significantly lower $(59 \%$ and $67 \%$ prediction values, respectively). For example, France (PDI $=69$ and $\mathrm{UAI}=86$ ) found that during the COVID-19 pandemic, $60 \%$ of the French fear that their family and friends will become sick with COVID-19 and 69\% worry that COVID-19 will consist of continuous outbreaks in the future and the country will lock down, which will continue to affect the country's economy. In Greece (PDI = 60 and UAI = 100), the first wave of the coronavirus outbreak in early 2020 significantly affected Greek daily life, perceptions, and 
behaviors. Vatavali et al. [47] found that Greeks had increased stress and fear of the changes that would affect them. However, most respondents were reluctant to respond to many changes in their lifestyles and behaviors.

In summary, in countries that have high power distance (PDI), their citizens will be less satisfied and have less trust in democracy, government, their own future, and the country's future during the COVID-19 pandemic. Having high uncertainty avoidance (UAI) resulted in people being pessimistic about their future and the future of their countries. However, indulgence (IVR) makes people more satisfied and trusting of democracies and their governments.

\section{4-3- Working during COVID-19: Job Security, Job Worry, and Working from Home (WFH) Satisfaction}

Figure 5 shows that countries with higher individualism (IDV) felt that job security was not less significant (32\% prediction value). This is because organizations view all employees as economic persons; at the same time, employees see themselves as human capital. Work is the exchange of benefits between employers and employees; if a company lays off its employees, the organization will be less productive [48]. For example, in the Netherlands (IDV $=80$ ), during the COVID-19 pandemic, the lives of the Dutch have not changed so much; they focus strongly on keeping people employed and working and supporting hard-hit sectors, so they opted for a softer and more relaxed lockdown than other EU member countries. The goal was to avoid the economy coming to a complete standstill. The Netherlands previously had a relatively better economy than many EU members, because of the relatively high focus on economic services and the social and digital economy, coupled with less stringent lockdowns [49]. Therefore, the Dutch feel their jobs are secure. They can work from home; but in the case of those who cannot work from home, their companies have conditions for employees to achieve social distancing of 1.5 meters. Employees with high individualism have a high degree of personal responsibility for controlling their behavior and lives safely.

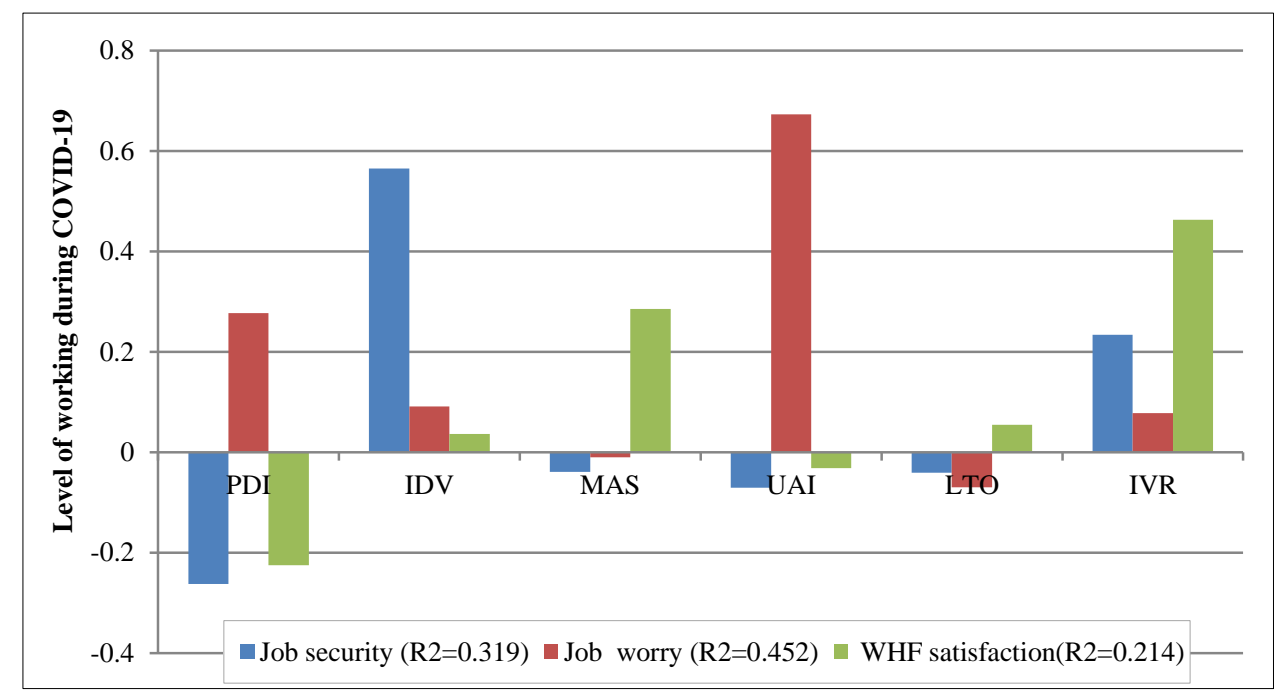

Figure 5. Working during COVID-19

Job worry asked about their concern regarding returning to their jobs. Latin Europeans with higher uncertainty avoidance (UAI) will have significantly higher anxiety in their works (45\% prediction value), e.g., Portugal (UAI = 99). The latest lockdown, effective January 15, 2021, affected jobs across the country, especially jobs that depend on tourism. Women and those without a university degree were most affected, including inexperienced workers being denied employment. The unemployment rate in Portugal is increasing rapidly. Workers panicked from being in lockdown and received two-thirds of their salaries in the first three phases of the 2020 pandemic, and service workers were the most worried about their jobs. Lima and Carrilho [50] said "in the services, not only was the decline more profound, but the recovery was more tenuous. It follows that the recovery in $\mathrm{V}$ that occurred at an aggregate level did not occur in general in services, in particular in activities related to tourism such as accommodation and food service activities, and also in transportation and storage."

The French $(\mathrm{UAI}=86)$ were very anxious about their jobs during the lockdown. There was much unemployment because businesses had to be temporarily closed, so the unemployment rate rose sharply in the second half of 2020 to 9\%. Young French are the most worried about their jobs; the unemployment rate was $60 \%$ in the first lockdown period. They worried since they were losing jobs and applied for new jobs but were rejected everywhere, while many employers had no vacancies. As a result, they do not have enough money to pay rent, and some had to use savings or loans to cover expenses. The French were worried about losing their jobs or being laid off as well as financial hardships that will follow [51]. Moreover, people who were involuntarily unemployed during the COVID-19 outbreak were more likely to develop mental disorders than those who were in quarantine and those who were voluntarily separated from their jobs [52]. 
For WHF satisfaction, countries with higher indulgence (IVR) had significantly higher satisfaction with WFH (21\% predictive value) because they are always happy, optimistic, feel in control of what is happening, want freedom and liberty, and prioritize free time and relaxation. This is consistent with the research of Reizer et al. [53], who found that laughing, optimism and a sense of humor lead to well-being during the COVID-19 lockdown period. People working remotely with technology are more positive than negative because of flexibility, efficiency, and effectiveness. Employees are satisfied and excited with the novelty of working [54]. Therefore, working from home can prevent COVID-19 patients from having more personal time and freedom. At the same time, businesses see it as a good opportunity for creating facilities to work at home. It is a win-win for both organizations and employees [31]. For example, in Finland (IVR = 57), Kinnunen [55] found that more than 50 percent of Finnish employees managed better when working from home and felt that balancing work and private life is easier. Similar to Belgians (IVR = 57), Van Herreweghe [56] found that $62 \%$ of employees are still employed during lockdown but working from home and there was a higher percentage of remote working in Europe.

This issue indicates that people in countries with higher individualism (IDV) feel that their jobs are not less stable and that countries with higher indulgence (IVR) have higher satisfaction with WFH. People in countries with higher uncertainty avoidance (UAI) will be more worried about their work.

\section{4-4- Financial Situation}

They were questions about the current financial status of the household and the expectations of the household's financial status in the future. Figure 6 presents countries with higher power distance (PDI) perceived as having an increasingly worse current financial situation (65\% prediction value) and that the situation will be significantly worse in the future (55\% predictive value). Most of these countries in Eastern Europe have poor economies, high inequality, low income when people are unemployed or financial insecurity, and they will clearly be worse off financially. They do not expect the family's financial situation to be better in the short term. For example, in Slovakia (PDI = 100), almost $48 \%$ of Slovakian respondents reported a deterioration, with more women than men, and almost $60 \%$ of working respondents reported a decrease in their income during the pandemic and lockdown [57]. Therefore, they perceived that the household's current financial situation was worse.

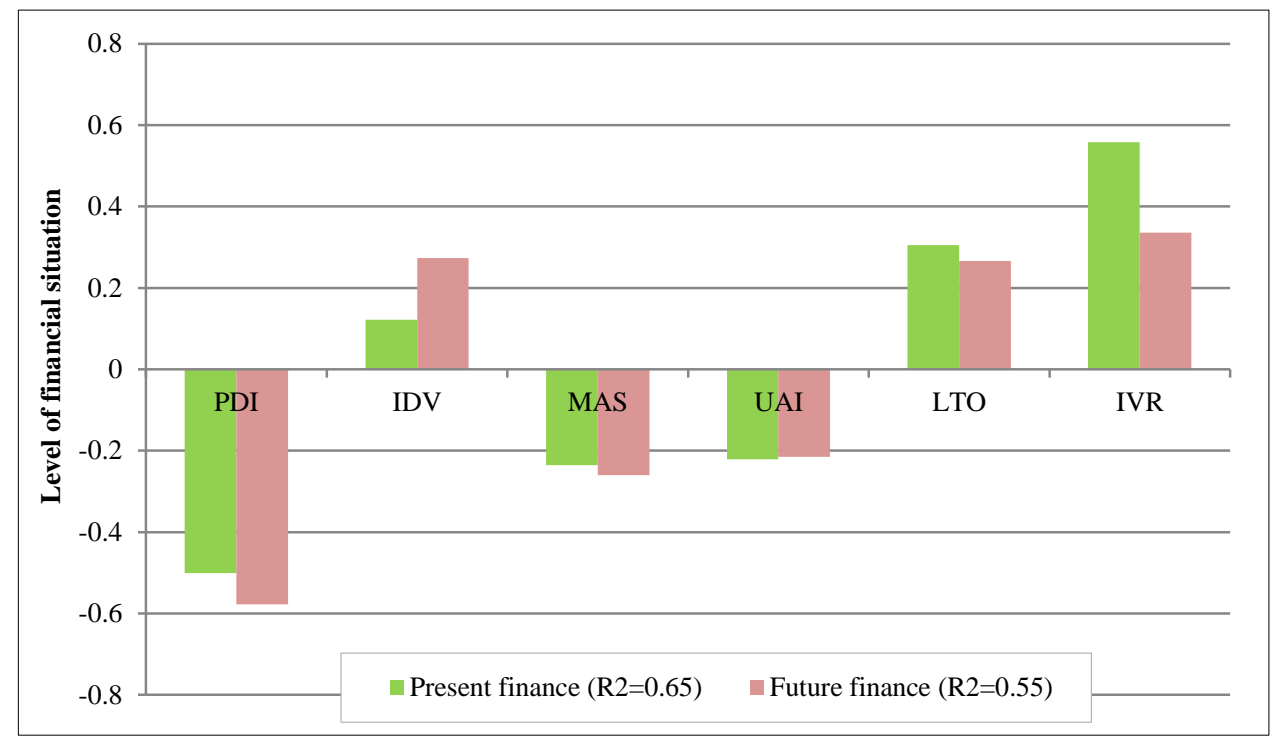

Figure 6. Financial situation

It was also found that countries with higher long-term orientation (LOT) were not significantly worse in their present financial status (65\% predictive value). Because they have the ability to adapt and focus on stability, they are thrifty, save, spend carefully, and invest for the future. For example, Belgium has a high score (LOT = 82), indicating that they save and always have enough money for their households. During the COVID-19 pandemic, permanent and temporary employees still have stable incomes, and no wage cuts were reported in Belgium [56]. Therefore, Belgians are less worried about their current financial situation.

However, in countries with higher indulgence (IVR), expectations for household finances were not worse at the present and are expected to be significantly better in the future (65\% and 55\% prediction values). This is because indulgent people tend to be optimistic and seek happiness in their lives. Along with the countries that provide good welfare, they have a positive expectation that in the future, their household's financial situation will be good and will be better. For example, in Sweden (IVR = 78), the Swedish government adapts or is flexible in the form of financial assistance during the crisis. In the beginning, a short-term work allowance system was used, but following a serious 
outbreak of COVID-19, the government switched to a temporary reinforcement of the short-term work system. Therefore, Swedish people are confident that their financial status will not be worse, but will be better. These findings are consistent with Chhatwani [58], who found that personal control, conscientiousness (long-term orientation), and openness to experience (indulgence) have a positive effect on financial well-being.

Therefore, countries with high power distance (PDI) perceived their present financial status to be worse and that it would not be better in the future. However, countries with high long-term orientation (LTO) do not have a worse financial status at present, and countries with high indulgence (IVR) do not worry about the current financial situation of the household and expect their household finances to be better in the future.

\section{4-5-Supporting during COVID-19. Financial Situation: Financial Support and Other Support}

Figure 7 shows that countries with higher long-term orientation (LOT) and higher indulgence (IVR) needed significantly less financial support ( $36 \%$ prediction value). This is because people received adequate government support in both normal and critical times. For example, Belgium (LOT = 82) has enough savings and adequate government financial assistance. In Denmark (IVR = 70), the people also helped each other in the form of volunteers and did not depend only on their government. The Danish government has also received cooperation from many sectors or partners that cooperate in helping Danes [44].

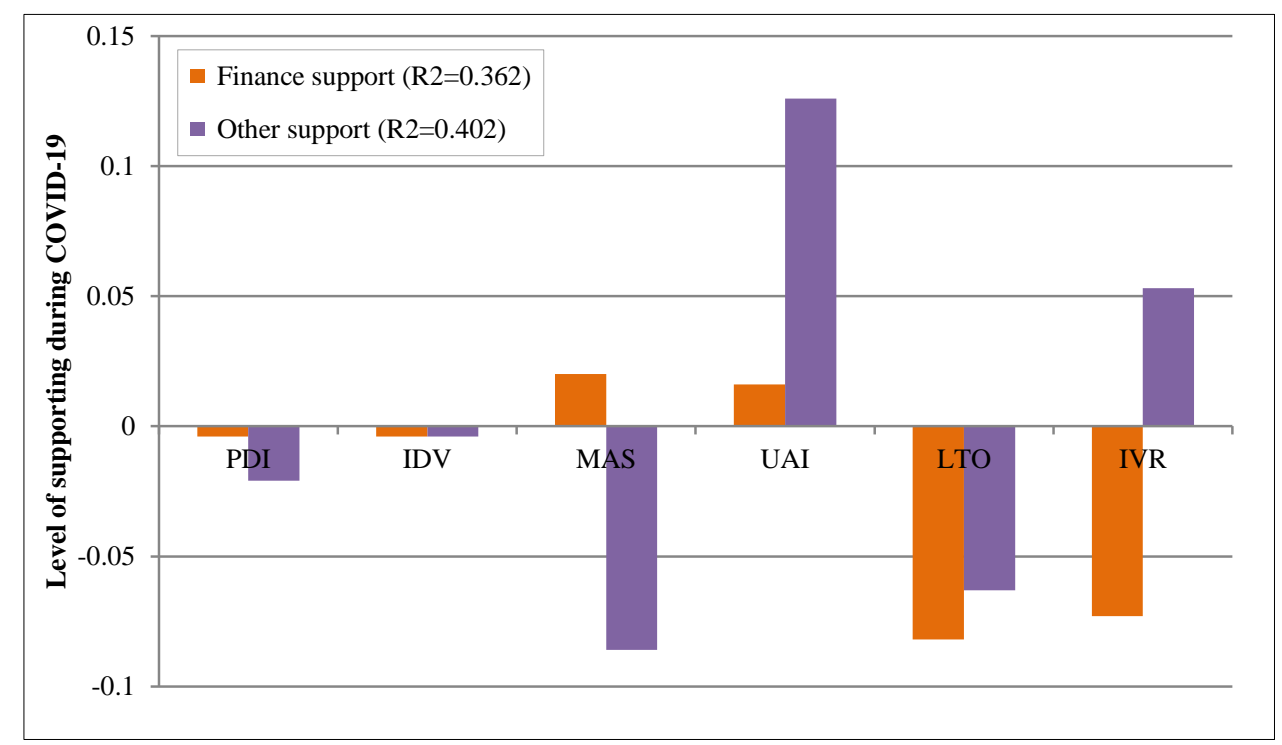

Figure 7. Supporting during COVID-19

However, countries that have higher uncertainty avoidance (UAI) are significantly in need of other types of welfare support $(40 \%$ prediction value), such as Slovenia (UAI $=88)$. Its economy has deteriorated since 2009 and became worse in 2020 due to the impact of the COVID-19 epidemic (GDP decreased by 14\%) [59]. Therefore, the government wanted to provide financial assistance and other welfare such as employment, financial assistance to households and businesses. Welfare was provided in the form of credit support, direct transfers, and tax allowances. This government assistance made people confidence that they could live in times of crisis. Hafner-Fink and Uhan [60] found that Slovenians and their families suffered from material deprivation, struggled to make ends meet and believed that social inequalities should be reduced.

However, it was also found that countries with higher masculinity (MAS) also have significantly less need for other support (40\% predictive value). This is because they value monetary rewards, work for money or material goods, are competitive, and want to win. Therefore, they prefer financial assistance rather than welfare or other assistance, such as Austria (MAS = 79), in which the level of wage setting of Austrians has not been impacted by the pandemic; they receive a subsidy in the form of "Corona" bonuses that are one-rate and tax-free and operate on all groups of employees equally [61]. It is good for the cultural emphasis on equity.

In summary, countries with higher long-term orientation (LOT) and higher indulgence (IVR) needed less financial support. However, countries with higher uncertainty avoidance (UAI) were increasingly in need of other welfare support, while people from masculine (MAS) countries needed less other support.

\section{4-6- Health Care System during COVID-19}

There is trust in the country's health care system and vaccination plan. Figure 8 shows countries with a higher power distance (PDI) in which confidence in the health care system was significantly lower (49\% prediction value), 
such as Bulgaria (PDI = 70), which has a low budget for health care and has the highest per capita death rate in the European Union (the EU) [62]. This made the Bulgarian public health system less available and restricted access to medical care for the poor. At present, thousands of Bulgarian health care workers are finding better-paying jobs in Western Europe, which has reduced the health care workforce during the COVID-19 pandemic. Even though Bulgaria has received substantial investment from international organizations such as the EU to upgrade medical infrastructure, these funds have done little to ensure that it has a thriving health care workforce. In the health care system in Bulgaria, more work still needs to be done to ensure that all citizens are receiving quality care. It is important that the government devotes more resources to health care in the nation [42].

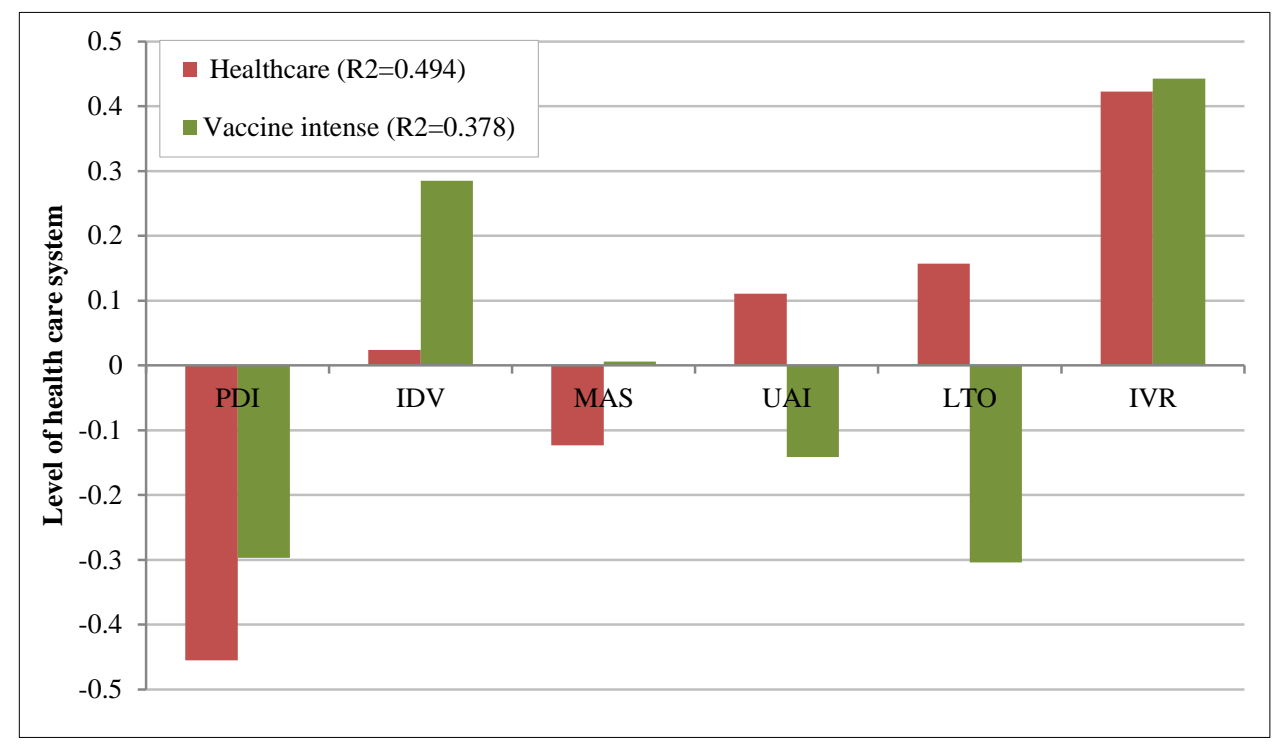

Figure 8. Health care system during COVID-19

However, countries with higher indulgence had significantly more confidence in the health care system and vaccine plans (49\% and 38\% prediction values). For example, in Denmark (IVR =70), where all Danes are provided with standard, equal, and free health care, citizens have access to treatment and diagnosis and can choose the hospital according to their preference. The Danish health care system is more effective than other developed countries, such as the United States and other European countries [63]. Approximately nine of ten Swedes (IVS $=78$ ) were willing to receive vaccines because they were optimistic, confident in the effectiveness of the vaccines, wanted the country to return to life and were free and happy to be living a normal life.

In conclusion, countries with high power distance (PDI) have a poor perception of the health care systems. However, countries with high indulgence (IVR) had more confidence in the health care system and greater willingness to receive the vaccination.

\section{5- Discussion}

This research could answer the question of how national cultures affect the quality of life of Europeans during the COVID-19 pandemic, which is consistent with Hofstede in some ways and contrasts with Hofstede [8, 9] and some studies as follows:

High Power Distance (PDI) significantly negatively affects perceived quality of life during the COVID-19 pandemic on well-being, life satisfaction, low trust in democracy and government, and a lack of belief in their future and that of their countries. There were also more financial problems both at present and in the future, and they did not trust the health systems of their countries. The empirical factors of high power distance are (a) inequality and (b) strict measures, most of which are in Eastern Europe and Latin Europe. In particular, Eastern European countries that do not have a traditional democratic way of life and have a small middle class due to inequality in decentralization have high power distance [8]. Those affected by inequality include the elderly, women, young people, the poor, the homeless, and immigrants, including the unemployed during the pandemic. Their financial status remains dire, and they need adequate social protection measures because their income distribution in society is very uneven [8]. Oakley et al. (2021) [33] found that the COVID-19 pandemic has further exacerbated existing healthcare inequalities for disabled people, probably contributing to disproportionate increases in morbidity and mortality, mental health and behavioral difficulties, and reduced quality of life. [64] In addition, the government imposed strict measures without public participation, so many countries have protested against the strict measures. People did not agree with the government's measures. This is different from their normal behavior, which might also lead to social unrest. 
However, the studies of Dheer et al (2021) [65], Voegel and Wachsman (2021) [66], and Gupta et al (2021) [67] found that high power distance has a negative effect on the number of COVID-19 cases over time. The number of cases is lower than that in low-power distance countries, which means high power distance is able to control the spread of COVID-19 (Han et al, 2020) [12]. The people obeyed and followed the measures of their leaders. Many studies have found that high power distance countries have a lower number of COVID-19 cases than low power distance countries. However, this study found that it had a negative effect on the quality of life or reduced the quality of life of Europeans during the COVID-19 pandemic. This is because a high power distance culture creates power inequality and unequal distribution of resources, especially during times of crisis. This made people dissatisfied with their quality of life and distrusful of the administration and the measures of the governments and institutions.

Uncertainty Avoidance (UAI) leads to reduced well-being, a lack of trust in one's personal future and the future of their countries, greater worry about their jobs and the need for other benefits in addition to money during this difficult time.

The findings follow the cultural dimension of Hofstede [8], where people from high uncertainty avoidance cultures have higher levels of stress and anxiety: "Uncertainty avoidance has to do with the way that a society deals with the fact that the future can never be known: should we try to control the future or just let it happen? This ambiguity brings with it anxiety." The emergence of this disease is different from their regular lives, making them uneasy, causing panic and perceiving that the risk was higher. This is similar to Messner and Payson (2021) [68], who found that uncertainty avoidance had a positive effect on public panic during COVID-19. Consistent with the research of Voegel and Wachsman (2021) [66], countries with higher uncertainty avoidance had significantly higher rates of COVID-19 cases.

However, this research differs from others; for example, Huynh (2020)[69] found that a country with a higher uncertainty avoidance index from the Hofstede (2001) dimension made people strictly follow the rules by avoiding gathering in public areas or strictly complying with swift quarantine measures and effective containment of COVID19 cases (Kumar, 2021) [70]. Countries with high levels of uncertainty avoidance have the ability to control the spread of the epidemic better than a country with low levels of uncertainty avoidance because people have more "tolerance" (Mattaa et al, 2021) [71].

It can be concluded that people who have high uncertainty avoidance are highly anxious about COVID-19, a new phenomenon, and do not know when it will end. In addition, governments have new measures that are different from the past; for example, the first epidemic had strict measures, but governments acted late in the face of the second outbreak because they were worried that the country's economy would be affected by the lockdown measures; that is, the governments are also trying to avoid high uncertainty. As a result, people cannot predict with the effects of the pandemic, reducing mental well-being, leading to uncertainty about one's future and the country and the need for other assistance to ensure the stability of their lives.

Indulgence (IVR) has a positive effect on the quality of life of Europeans during the COVID-19 pandemic. It resulted in people's trust in democracy and their government, satisfaction with working from home, not worrying about their present finances, expecting their household finances to be better in the future, needing less financial assistance, and being satisfied with the health care system of their countries including wanting to be vaccinated. They are living life with a fun, positive attitude, always looking at the world in an optimistic way, paying more attention to free time, doing what they want, and wanting freedom; most of them are Scandinavian or Nordic countries.

However, many researchers have found that indulgence has an effect on the increase in the number of COVID-19 cases, such as Gökmen et al. (2021) [15], Ibanez and Sisodia (2020) [17], and Voegel and Wachsman (2021) [66]. Because people have less control over their own desires, they enjoy being with their friends and need happiness even in times of crisis.

Despite different results, indulgence helps people to be satisfied with their quality of life even in times of crisis.

They think they can control themselves or that everything is caused by internal factors or internal loci of control. They are optimistic and can find happiness even in difficult times. In other words, indulgences may be necessary for those who are living.

Long-term Orientation (LOT) was found to have a positive effect on the financial situation of Europeans during the crisis. They do not have problems with either the present or future finances, and they want less financial support during the COVID-19 outbreak. They do not experience much financial suffering because they have savings or reserves for household expenses. This result is aligned with Ibanez and Sisodia (2020) [17], who found that countries with a high long-term orientation seem to be better prepared to respond to cyclical recurrent crisis scenarios. RojasMéndez (2021) [72] found that the higher the score in the long-term orientation, the lower the worry levels expressed during the COVID-19 pandemic. 
Individualism (IDV) was correlated with confidence in their jobs, which were very secure due to self-reliance, adherence to the principle of rationality, and self-efficacy. One of the main reasons was that individualistic organizations hired people in their capacities. The mobility of jobs or organizations is not difficult in this society; thus, they feel secure in their jobs, even in times of crisis. A large number of studies have found that individualism is positively correlated with COVID-19 prevalence, mortality, and case-fatality rates [15, 17, 73, 74]. However, the individual also makes people feel confident in their work while they are alive and able to work.

Masculinity (MAS) countries did not want other support during the COVID-19 pandemic, because people in these countries prefer money and higher pay and they would rather work than take a break and get government assistance. This is consistent with the work of Dheer et al. (2021) [65] who found that masculinity has a negative impact on the growth rate of COVID-19 cases. It shows that masculine culture makes the individual strong and want to overcome obstacles.

\section{6- Conclusions}

This research aimed to provide relevant information for stakeholders to have a good quality of life during the COVID-19 pandemic, which has not yet ended, even if there is already a vaccination. They should reduce the high power distance, which decreases inequality, have low uncertainty avoidance by reducing anxiety, increasing optimism, and making long-term plans for dealing with future uncertainties. Recommendations are as follows:

Short-term Implementation: Urgent economic assistance is required to relieve the anxiety of those who avoided high uncertainty. Policy-makers should have short-term fiscal measures to remedy and reduce the burden of those affected by COVID-19, for example, giving money to help those who have been laid off, short-term employment for young people, giving benefits to businesses that have ceased operations, and paying companies affected by lockdown measures for them to retain their employees. There are measures to support low-interest loans and measures to drive liquidity in the financial system to help small- and medium-sized businesses or self-employment affected by the COVID-19 outbreak.

In employment, there must be measures that are fair for both the employers and the employees, such as working from home, which must not ruin the personal life of employees, having flexible work schedules, and providing safe workplaces from the spread of COVID-19. Employers pay compensation and healthcare welfare for home-based employees, including supporting technologies and resources for those who work or study at home. In addition, they have to take care of public health. Healthcare policies should be given to vulnerable groups such as the elderly, the homeless, and the poor in slums faster than to other groups because they risk infection and have difficulties accessing the healthcare system. Getting vaccinated early will protect against the risk and spread of the epidemic through them. Psychological care should also be taken, such as feelings of loneliness, depression, and tension. Communities should establish mental health counseling hotlines or centers with the help of community volunteers. They should take care of patients from COVID-19, those who lost family members, people in quarantine, laid-off employees, or even those who work from home, especially women and the elderly. Most importantly, policy-makers need to formulate policies and implement them equally. When people receive equal treatment, they are confident in their quality of life.

Intermediate Term Implementation: There is a need to prepare for future changes and reduce anxiety in ambiguous situations by promoting lifelong learning to provide people with the knowledge and skills needed in the future, such as digital, information technology, and logistics skills. In particular, employees who have been laid off or unemployed should be retrained or reskilled to have new skills or multiple skills that give them more potential to work in different new careers.

Long-term Implementation: A shift is required from cultures that have a negative impact on quality of life to cultures that have a positive impact. (a) Long-term orientation by being thrifty, saving, and investing in the future. Saving money for themselves and their families can be done smoothly in case of an emergency. They do not have to wait for government assistance, which may be late or inadequate. (b) Optimism and happiness in the present are increasing the quality of life. To be optimistic is to have faith and the expectation that good things will happen even if people are in a difficult, challenging or tight situation. Optimistic people have a higher quality of life than those with low levels of optimism or even pessimists [75]. It not only affects the mind but also affects the body. Communities should organize activities frequently that make their citizens happy and full of laughter and joy.

Future Study: This study examined the quality of life of Europeans during the COVID-19 pandemic, which is still alive. The findings may or may not be consistent with research on case increases and mortality rates. But it may be useful for preventing COVID-19 because the good quality of life has been well affected in the long-term among pandemics. Therefore, further studies on national cultures and epidemics should be conducted in longitudinal research to be a guideline for preventing and rescuing in a crisis. 


\section{6-1-Limitation}

Eurofound (2020-2021) studied the quality of life of 27 European countries that are members of the European Union. However, this research has been conducted based on data from 26 countries. Cyprus was not included because its six cultural dimensions were not available. Quality of life data on some issues, Eurofound did not survey all 3 phases, so the researcher used the data as available and analyzed the relationship with the independent variables from Hofstede's 6 cultural dimensions.

\section{7- Declarations}

\section{7-1-Author Contributions}

Conceptualization, S.K. and J.R.; methodology, S.K.; software, J.R.; formal analysis, S.K. and J.R; writingoriginal draft preparation, S.K.; writing-review and editing, J.R. All authors have read and agreed to the published version of the manuscript.

\section{7-2-Data Availability Statement}

The data presented in this study are available on request from the corresponding author.

\section{7-3- Funding}

The authors received no financial support for the research, authorship, and or publication of this article.

\section{7-4- Conflicts of Interest}

The authors declare that there is no conflict of interests regarding the publication of this manuscript. In addition, the ethical issues, including plagiarism, informed consent, misconduct, data fabrication and/or falsification, double publication and/or submission, and redundancies have been completely observed by the authors.

\section{8- References}

[1] World Health Organization (2021). WHO Coronavirus (COVID-19) Dashboard. Available online: https://covid19.who.int/ (accessed on September 2021).

[2] Al Dhaheri, A. S., Bataineh, M. F., Mohamad, M. N., Ajab, A., Al Marzouqi, A., Jarrar, A. H., Habib-Mourad, C., Jamous, D. O. A., Ali, H. I., Al Sabbah, H., Hasan, H., Stojanovska, L., Hashim, M., Elhameed, O. A. A., Obaid, R. R. S., ElFeky, S., Saleh, S. T., Osaili, T. M., \& Ismail, L. C. (2021). Impact of COVID-19 on mental health and quality of life: Is there any effect? A crosssectional study of the MENA region. PLoS ONE, 16(3 March). doi:10.1371/journal.pone.0249107.

[3] Cepel, M., Gavurova, B., Dvorský, J., \& Belas, J. (2020). The impact of the COVID-19 crisis on the perception of business risk in the SME segment. Journal of International Studies. doi:10.14254/2071-8330.2020/13-3/16

[4] Grané, A., Albarrán, I., \& Merchán, D. E. (2021). Impact of pandemic on European well-being: Visualizing scenarios from the share database. International Journal of Environmental Research and Public Health, 18(9). doi:10.3390/ijerph18094620.

[5] European Foundation for the Improvement of Living and Working Conditions (Eurofound). Working life in the COVID-19 pandemic. Available online: https://www.eurofound.europa.eu/sites/default/files/ef_publication/field_ef_document/ef2 1070en.pdf (accessed on September 2021).

[6] Ahrendt, D., Cabrita, J., Clerici, E., Hurley, J., Leončikas, T., Mascherini, M., ... \& Sándor, E. (2020). Living, working and COVID-19. Publications Office of the European Union, Eurofound. doi:10.2806/467608.

[7] House, R. J., Hanges, P. J., Javidan, M., Dorfman, P. W., \& Gupta, V. (Eds.). (2004). Culture, leadership, and organizations: The GLOBE study of 62 societies. Sage publications, New York, United States.

[8] Geert Hofstede. (2021). Hofstede Insights. Available online: https://www.hofstede-insights.com/country/south-korea/ (Accessed on September 2021).

[9] Geert Hofstede. (2011). Dimensionalizing Cultures: The Hofstede Model in Context. Online Readings in Psychology and Culture, 2(1). doi:10.9707/2307-0919.1014.

[10] Kang, S. M., Shaver, P. R., Sue, S., Min, K. H., \& Jing, H. (2003). Culture-Specific Patterns in the Prediction of Life Satisfaction: Roles of Emotion, Relationship Quality, and Self-Esteem. Personality and Social Psychology Bulletin, 29(12), 1596-1608. doi:10.1177/0146167203255986.

[11] Schalock, R. L., Verdugo, M. A., Jenaro, C., Wang, M., Wehmeyer, M., Jiancheng, X., \& Lachapelle, Y. (2005). Crosscultural study of quality of life indicators. American Journal on Mental Retardation, 110(4), 298-311. doi:10.1352/08958017(2005)110[298:CSOQOL]2.0.CO;2. 
[12] Han, L., Wang, R., \& Siau, K. (2020). Effects of National Culture on COVID-19 Pandemic Control and Management. 41st International Conference on Information Systems, ICIS 2020, Hyderabad, India.

[13] Cao, C., Li, N., \& Liu, L. (2020). Do national cultures matter in the containment of COVID-19? International Journal of Sociology and Social Policy, 40(9-10), 939-961. doi:10.1108/IJSSP-07-2020-0334.

[14] Maaravi, Y. Tragedy of the Commons: The Potential Role of Individualism in the Spread of COVID-19. Available online: https://blog.frontiersin.org/2021/03/19/tragedy-of-the-commons-the-potential-role-of- individualism-in-the-spread-of-covid19/ (accessed on June 30, 2021).

[15] Gokmen, Y., Baskici, C., \& Ercil, Y. (2021). The impact of national culture on the increase of COVID-19: A cross-country analysis of European countries. International Journal of Intercultural Relations, 81(March 2021), 1-8. doi:10.1016/j.ijintrel.2020.12.006.

[16] Oey, E., \& Rahardjo, B. S. (2021). Does culture influence our ways in handling COVID-19? International Journal of Sociology and Social Policy, 41(11-12), 1149-1169. doi:10.1108/IJSSP-02-2021-0051.

[17] Ibanez, A., \& Sisodia, G. S. (2020). The role of culture on 2020 SARS-CoV-2 Country deaths: a pandemic management based on cultural dimensions. GeoJournal, 3, 1-17. doi:10.1007/s10708-020-10306-0.

[18] Terzi, A. R. (2011). Relationship between power distance and autocraticdemocratic tendencies. Educational Research and Reviews, 6(7), 528-535.

[19] Kito, M., Yuki, M., \& Thomson, R. (2017). Relational mobility and close relationships: A socioecological approach to explain cross-cultural differences. Personal Relationships, 24(1), 114-130. doi:10.1111/pere.12174.

[20] Erman, A., \& Medeiros, M. (2021). Exploring the Effect of Collective Cultural Attributes on Covid-19-Related Public Health Outcomes. Frontiers in Psychology, 12. doi:10.3389/fpsyg.2021.627669.

[21] Calori, R. and F. Seidel. (1997). The Dynamic Management in Europe.” In Calori R. and P. de Wood (Eds). A European Management Model: Beyond Diversity, 55-78. Prentice Hall, Hertfordshire, U.K.

[22] Schwartz, S. H. (2008). Cultural value orientations: Nature and implications of national differences. The Hebrew University, Jerusalem, Israel.

[23] Trompenaars, F., \& Hampden-Turner, C. (2011). Riding the waves of culture: Understanding diversity in global business. Nicholas Brealey International, London, UK.

[24] WHO. (2004). The World Health Organization Quality of Life (WHOQOL)-BREF. World Health Organization. Available online: https://www.who.int/publications/i/item/WHO-HIS-HSI-Rev.2012.03 (accessed on June 1, 2021)

[25] Andrews, F. M., \& Withey, S. B. (1976). Social Indicators of Well-Being. Springer, Boston, MA, United States. doi:10.1007/978-1-4684-2253-5.

[26] Chamberlain, K. (1985). Value dimensions, cultural differences, and the prediction of perceived quality of life. Social Indicators Research, 17(4), 345-400. doi:10.1007/BF00290321.

[27] Diener, E. (1994). Assessing subjective well-being: Progress and opportunities. Social Indicators Research, 31(2), $103-157$. doi:10.1007/BF01207052.

[28] Doyal, L., \& Gough, I. (1984). A theory of human needs. Critical Social Policy, SAGE Publishing, 4(10), 6-38. doi:10.1177/026101838400401002.

[29] Maslow, A. H. (1943). A theory of human motivation. Psychological review, 50(4), 370. doi:10.1037/h0054346.

[30] Hunt, S. M., \& McKenna, S. P. (1992). The QLDS: A scale for the measurement of quality of life in depression. Health Policy, 22(3), 307-319. doi:10.1016/0168-8510(92)90004-U.

[31] Eurofound. (2021). Living, working and COVID-19 (Update April 2021): Mental health and trust decline across EU as pandemic enters another year. 19 (April), 1-21. Available online: https://www.eurofound.europa.eu/publications/report/2021/ living-working-and-covid-19-update-april-2021 (accessed on April 2021).

[32] France 24. Hungary Kitchen Fills Welfare Gap for COVID Jobless. Available online: https://www.france24.com/en/livenews/20210108-hungary-kitchen-fills-welfare-gap-for-covid jobless (accessed on July 2021).

[33] Oakley, B., Tillmann, J., Ruigrok, A., Baranger, A., Takow, C., Charman, T., Jones, E., Cusack, J., Doherty, M., Violland, P., Wroczyńska, A., Simonoff, E., Buitelaar, J. K., Gallagher, L., \& Murphy, D. G. M. (2021). COVID-19 health and social care access for autistic people: European policy review. BMJ Open, 11(6). doi:10.1136/bmjopen-2020-045341.

[34] Turlan, F. France: Working Life in the COVID-19 Pandemic 2020. Available online: https://www.eurofound.europa.eu/sites/ default/files/wpef21015.pdf (accessed on September 2021). 
[35] Hallaert, J.-J. (2020). Poverty and Social Protection in Bulgaria. IMF Working Papers, $2020(147)$, 1. doi:10.5089/9781513550190.001.

[36] Brain, S., \& Deloitte. Exploring the Sacrifice of Work-Life Balance in Times of Crisis: Lessons from a Greek Case Study. Available online: https://www2.deloitte.com/au/en/blog/diversity-inclusion-blog/2020/exploring-sacrifice-work-life-balancetimes-crisis.html (accessed on June 2021).

[37] Kousta, E. (2020). Industrial relations and social dialogue, Greece: Working Life in the Pandemic 2020. Available online: https://www.eurofound.europa.eu/sites/default/files/wpef21017.pdf (accessed on June 2021).

[38] Bittmann, F. (2021). How Trust Makes a Difference: The Impact of the First Wave of the COVID-19 Pandemic on Life Satisfaction in Germany. Applied Research in Quality of Life, 1-17. doi:10.1007/s11482-021-09956-0.

[39] Polyakova, A., Taussig, T., Reinert, T., Kirişci, K., Sloat, A., Kirchick, J., Hooper, M., Eisen, N., \& Kenealy, A. (2019). The anatomy of illiberal states: assessing and responding to democratic decline in Turkey and Central Europe, 1-55. The Brookings Institution. Available online: https://www.brookings.edu/wp-content/uploads/2019/02/illiberal-states-web.pdf (accessed on June 2021).

[40] Kinowska-Mazaraki, Z. (2021). The polish paradox: From a fight for democracy to the political radicalization and social exclusion. Social Sciences, 10(3), 1-16. doi:10.3390/socsci10030112.

[41] Czarzasty, J. (2021). Poland: Working Life in the COVID-19 Pandemic 2020. Available online: https://www.eurofound.europa.eu/sites/default/files/wpef21027.pdf (accessed on June 2021).

[42] Ribarova, E., \& Ivanova, V. (2021). Bulgaria: Working Life in the COVID-19 Pandemic 2020. Available online: https://www.eurofound.europa.eu/sites/default/files/wpef21008.pdf (accessed on June 2021).

[43] Euronews. Coronavirus: Polish President Duda Tests Positive for COVID-19. Available online: https://www.euronews.com/2020/10/24/coronavirus-polish-president-duda-tests-positive-for-covid-19 (accessed on June 2021).

[44] Hansen, M., \& Jørgensen, C. Denmark: Working Life in the Pandemic 2020. Available online: https://www.eurofound.europa.eu/sites/default/files/wpef21012.pdf (accessed on June 2021).

[45] Kurujitkosol, P. Danish Living: More is Less and Less is More. Available online: https://readthecloud.co/covid-19-denmark/ (accessed on June 2021).

[46] Ye, B., Hu, J., Xiao, G., Zhang, Y., Liu, M., Wang, X., Yang, Q., \& Xia, F. (2021). Access to Epidemic Information and Life Satisfaction under the Period of COVID-19: the Mediating Role of Perceived Stress and the Moderating Role of Friendship Quality. Applied Research in Quality of Life. doi:10.1007/s11482-021-09957-z.

[47] Vatavali, F., Gareiou, Z., Kehagia, F., \& Zervas, E. (2020). Impact of COVID-19 on urban everyday life in Greece. Perceptions, experiences and practices of the active population. Sustainability (Switzerland), 12(22), 1-17. doi:10.3390/su12229410.

[48] Dessler, Gary “Human Resource Management, Global Edition, 16th. Edition.” (2020). Pearson. Florida, United States.

[49] van der Graaf, A. (2020). Netherlands: Working Life in the COVID-19 Pandemic 2020. Available online: https://www.eurofound.europa.eu/sites/default/files/wpef21025.pdf (accessed on June 2021)

[50] Lima, M. da P. C., \& Carrilho, P. (2020). Portugal: Working Life in the COVID-19 Pandemic 2020. Available online: https://euagenda.eu/upload/publications/wpef21028.pdf (accessed on June 2021).

[51] France 24. (2020). Covid-19: Half of France's Private Sector Workers Now Unemployed. Available online: https://www.france24.com/en/20200422-covid-19-half-of-france-s-private-sector-workers-on-temporary-unemploymentscheme (accessed on July 2021).

[52] Yao, R., \& Wu, W. (2021). Mental Disorders Associated with COVID-19 Related Unemployment. Applied Research in Quality of Life. doi:10.1007/s11482-021-09950-6.

[53] Reizer, A., Munk, Y., \& Katz Frankfurter, L. (2022). Laughing all the way to the lockdown: On humor, optimism, and wellbeing during COVID-19. Personality and Individual Differences, 184(January). doi:10.1016/j.paid.2021.111164.

[54] Beňo, M. (2021). The Advantages and Disadvantages of E-working: An Examination using an ALDINE Analysis. Emerging Science Journal, 5 (Special issue), 11-20. doi:10.28991/esj-2021-sper-02.

[55] Kinnunen, Amanda. (2020). Finland: Working Life in the COVID-19 Pandemic 2020. Available online: https://www.eurofound. europa.eu/sites/ default/files/wpef21014.pdf (accessed on July 2021).

[56] Herreweghe, V., \& Dries. (2020) Belgium: Working Life in the Pandemic 2020. Available online: https://www.eurofound. europa.eu/sites/default/files/wpef21007.pdf (accessed on July 2021) 
[57] Cziria, L., Bednárik, R., \& Kešelová, D. Slovakia: Working Life in the COVID-19 Pandemic 2020. Available online: https://euagenda.eu/upload/publications/wpef21030.pdf (accessed on June 2021).

[58] Chhatwani, M. (2022). Personal control and financial well-being among the elderly: Moderating role of the big five. Personality and Individual Differences, 184. doi:10.1016/j.paid.2021.111171.

[59] Damijan, J., Konings, J., \& Yergabulova, A. (2020). Increasing market power in Slovenia: Role of diverging trends between exporters and non-exporters. World Economy, 43(5), 1327-1345. doi:10.1111/twec.12932.

[60] Hafner-Fink, M., \& Uhan, S. (2021). Life and Attitudes of Slovenians during the COVID-19 Pandemic: The Problem of Trust. International Journal of Sociology, 51(1), 76-85. doi:10.1080/00207659.2020.1837480.

[61] Bernadette, A. (2020). Austria: Working Life in the COVID-19 Pandemic 2020. Available online: https://euagenda.eu/upload/publications/wpef21006.pdf (accessed on July 2021).

[62] Dzhambazova, B. (2021). Bulgaria's Health System on Brink of Collapse from Coronavirus Crisis. Politico. Available online: https://www.politico.eu/article/bulgaria-health-crisis-coronavirus-hospitals-deaths/ (accessed on July 2021).

[63] Social Progress Imperative, (2021). Global Index: Overview: Social Progress Index sizzle video. Available online: https://www.socialprogress.org/index/global (accessed on July 2021).

[64] Zhao, Y. J., Zhang, S. F., Li, W., Zhang, L., Cheung, T., Tang, Y. L., Ng, C. H., Yang, B. X., \& Xiang, Y. T. (2021). Mental health status and quality of life in close contacts of COVID-19 patients in the post-COVID-19 era: a comparative study. Translational Psychiatry, 11(1). doi:10.1038/s41398-021-01623-0.

[65] Dheer, R. J. S., Egri, C. P., \& Treviño, L. J. (2021). A cross-cultural exploratory analysis of pandemic growth: The case of COVID-19. Journal of International Business Studies, 52(9), 1871-1892. doi:10.1057/s41267-021-00455-w.

[66] Voegel, J., \& Wachsman, Y. (2021). The effect of culture in containing a pandemic: the case of COVID-19. Journal of Risk Research. doi:10.1080/13669877.2021.1986566.

[67] Gupta, M., Shoja, A., \& Mikalef, P. (2021). Toward the understanding of national culture in the success of non-pharmaceutical technological interventions in mitigating COVID-19 pandemic. Annals of Operations Research. doi:10.1007/s10479-02103962-z.

[68] Messner, W., \& Payson, S. E. (2021). Contextual factors and the COVID-19 outbreak rate across U.S. counties in its initial phase. Health Science Reports, 4(1). doi:10.1002/hsr2.242.

[69] Huynh, T. L. D. (2020). Does culture matter social distancing under the COVID-19 pandemic? Safety Science, 130. doi:10.1016/j.ssci.2020.104872.

[70] Kumar, R. (2021). Impact of Societal Culture on Covid-19 Morbidity and Mortality across Countries. Journal of CrossCultural Psychology, 52(7), 643-662. doi:10.1177/00220221211025100.

[71] Matta, S., Rogova, N., \& Luna-Cortés, G. (2022). Investigating tolerance of uncertainty, COVID-19 concern, and compliance with recommended behavior in four countries: The moderating role of mindfulness, trust in scientists, and power distance. Personality and Individual Differences, 186(111352). doi:10.1016/j.paid.2021.111352.

[72] Rojas-Méndez, J. I. (2021). Explaining People's Worry Levels during the Covid-19 Pandemic: An Analysis of SocioEconomic and Cultural Dimensions. Frontiers in Psychology, 12. doi:10.3389/fpsyg.2021.737917.

[73] Rajkumar, R. P. (2021). The relationship between measures of individualism and collectivism and the impact of COVID-19 across nations. In Public Health in Practice (Vol. 2). doi:10.1016/j.puhip.2021.100143.

[74] Maaravi, Y., Levy, A., Gur, T., Confino, D., \& Segal, S. (2021). "The Tragedy of the Commons": How Individualism and Collectivism Affected the Spread of the COVID-19 Pandemic. Frontiers in Public Health, 9. doi:10.3389/fpubh.2021.627559.

[75] Conversano, C., Rotondo, A., Lensi, E., Della Vista, O., Arpone, F., \& Reda, M. A. (2010). Optimism and Its Impact on Mental and Physical Well-Being. Clinical Practice \& Epidemiology in Mental Health, 6(1), 25-29. doi:10.2174/1745017901006010025. 